Article

\title{
Synthesis of MCM-41 Immobilized (Phenoxy)Imine Palladium(II) Complexes as Recyclable Catalysts in the Methoxycarbonylation of 1-Hexene
}

\author{
Saphan O. Akiri and Stephen O. Ojwach *(D) \\ School of Chemistry and Physics, University of KwaZulu-Natal, Private Bag X01, Scottsville, \\ Pietermaritzburg 3209, South Africa; akirisaphan88@gmail.com \\ * Correspondence: ojwach@ukzn.ac.za
}

Received: 28 December 2018; Accepted: 31 January 2019; Published: 2 February 2019

check for updates

\begin{abstract}
The immobilization of 2-phenyl-2-((3(tryethoxysicyl)propyl)imino)ethanol (HL1) and 4-methyl-2-(((3(triethoxysilyl)propyl)imino)methyl)phenol (HL2) on MCM-41 afforded the respective ligands HL1-MCM-41 (HL3) and HL2-MCM-41 (HL4). The treatment of complexes $\operatorname{Pd}(\mathbf{L 1})_{2}$ and $\operatorname{Pd}(\mathbf{L} 2)_{2}$ with MCM-41 afforded the immobilized complexes $\left(\operatorname{Pd}(\mathbf{L 1})_{2}\right)-\mathrm{MCM}-41$ (1) and $\left(\mathrm{Pd}(\mathrm{L} 2)_{2}\right)-\mathrm{MCM}-41$ (2) respectively. Separately, the reactions of HL3 and HL4 with $\mathrm{Pd}(\mathrm{NCMe})_{2} \mathrm{Cl}_{2}$ produced the immobilized complexes $\mathrm{Pd}(\mathrm{HL} 3) \mathrm{Cl}_{2}(3)$ and $\mathrm{Pd}(\mathbf{H L} 4) \mathrm{Cl}_{2}(4)$ respectively. The immobilized compounds were characterized by FT-IR, Transmission Electron Microscopy (TEM), Scanning Electron Microscopy (SEM), energy-dispersive X-ray (EDX), Thermogravimetric Analysis (TGA) and X-ray Powder Diffraction (XRD). All the complexes (1-4) formed active catalysts in the methoxycarbonylation of 1-hexene to give linear and branched esters. The catalysts were recycled four times without the loss of catalytic activity. Hot filtration experiments established the absence of leaching, and the heterogeneous nature of the active species was derived from mercury drop experiments.
\end{abstract}

Keywords: Palladium; complexes; immobilization; methoxycarbonylation; recycling

\section{Introduction}

Homogeneous catalysts have been used in a number of industrial processes largely due to their high selectivity and ease of understanding of the reaction kinetics and mechanisms [1]. However, the homogeneous systems do suffer from the lack of separation of the catalysts from the reaction mixture in addition to the lack of catalyst recycling. Heterogeneous catalysts, on the other hand, are easily recoverable, but they too have several drawbacks, mainly associated with low catalytic activities and poor selectivity [2]. This has necessitated a search for catalyst systems that can exploit the advantages and limit the disadvantages of both homogeneous and heterogeneous catalysts $[3,4]$. Thus, the immobilization of homogeneous catalysts to give a hybrid system which is recoverable and selective is currently of much interest in catalyst design and development [5,6]. To date, a number of methods of heterogenizing homogeneous catalysts have been adopted. These include the immobilization of homogeneous catalysts on insoluble solid supports such as silica [7], polymer [8], magnetic nanoparticles [9] as well as biphasic catalysis [10].

One notable approach that has been widely employed is the immobilization of metal complexes on mesoporous silica [11,12]. This is largely owed to the chemical and thermal stability of silica in addition to its relatively lower costs and availability [13]. Even though immobilized catalysts have been widely used in a number of organic transformation reactions such as olefin polymerization [14], Suzuki-Miyaura and Sonogashira cross coupling reactions [15-18], Heck coupling reactions [19], 
oligomerization [20] and hydrogenation reactions [21,22] among others, it is surprising that the methoxycarbonylation of olefins has witnessed very limited reports. Few examples include palladium(II) complexes bearing imidazole ionic ligand ionic liquids in the alkoxycarbonylation of aryl iodides as reported by Khedkar et al. [23]. In another finding, silica immobilized palladium catalysts of the (2-diphenylphosphino)ethane ligand were found to give a complete conversion of aryl halides with a $97 \%$ chemoselectivity towards ester products [24].

Owing to the significance of the methoxycarbonylation reactions in the production of domestic and industrial products such as detergents, cosmetics and pharmaceuticals [25,26], it is therefore important to design selective catalysts that can also be easily separated from the reaction mixture. We have currently embarked on the design of both homogeneous and immobilized palladium catalysts in the methoxycarbonylation of higher olefins. In one such report, we used palladium complexes of (phenoxy)imine ligands bearing silane alkoxy groups as homogeneous catalysts in the methoxycarbonylation of higher olefins [27]. In this current contribution, we report the application of palladium complexes immobilized on MCM-41 as recyclable catalysts in the methoxycarbonylation of 1-hexene. Thus, the syntheses and structural elucidation of these immobilized palladium(II) complexes, their catalytic activities in the methoxycarbonylation of 1-hexene and recycling experiments are discussed.

\section{Results and Discussion}

\subsection{Synthesis of Immobilized (Phenoxy)Imine Ligands and their Palladium(II) Complexes}

The treatment of ligands 2-phenyl-2-((3(tryethoxysicyl)propyl)imino)ethanol (HL1) and 4-methyl-2-(((3(triethoxysilyl)propyl)imino)methyl)phenol (HL2) with MCM-41 afforded the silica immobilized compounds HL1-MCM-41 (HL3) and HL2-MCM-41 (HL4) in good yields (Scheme 1). A convergent approach [12] was adopted to synthesize complexes $\left(\operatorname{Pd}(\mathbf{L 1})_{2}\right)-\mathrm{MCM}-41(\mathbf{1})$ and $\left(\operatorname{Pd}(\mathbf{L} 2)_{2}\right)-M C M-41(2)$ via the immobilization of the homogeneous complexes $\operatorname{Pd}(\mathbf{L} \mathbf{1})_{2}$ and $\operatorname{Pd}(\mathbf{L} 2)_{2}$ on MCM-41 support respectively (Scheme 1). On the other hand, complexes $\operatorname{Pd}(\mathbf{H L 3})\left(\mathrm{Cl}_{2}\right)(3)$ and $\operatorname{Pd}(\mathbf{H L} 4)\left(\mathrm{Cl}_{2}\right)(4)$ were synthesized from reactions of the respective immobilized ligands HL3 and HL4 with $\mathrm{PdCl}_{2}(\mathrm{NCMe})_{2}$ following the sequential protocol [28] as shown in Scheme 1. Attempts to use the sequential method to prepare complexes $\mathbf{1}$ and $\mathbf{2}$ did not materialize. Owing to the superiority of the sequential route [29] over the convergent method, no attempts were thus made to prepare complexes 3 and 4 via the convergent method.

The structural characterization of the immobilized compounds was performed using FT-IR, TGA, TEM, SEM-EDX and XRD. The FT-IR bending vibrations between $1306 \mathrm{~cm}^{-1}$ and $1365 \mathrm{~cm}^{-1}$ were assigned to the $\mathrm{Si}-\mathrm{O}-\mathrm{Si}$ bonds of the MCM-41 support and established a successful formation of the immobilized ligands HL3 and HL4 [30]. FT-IR spectra were also useful in the determination of the coordination of HL3 and HL4 to give the respective palladium(II) complexes 3 and 4. For instance, the $v(\mathrm{C}=\mathrm{N})$ signals in ligand HL4 and the corresponding complex 4 were observed at $1611 \mathrm{~cm}^{-1}$ and $1652 \mathrm{~cm}^{-1}$ respectively (Figures S2 and S6). These results echo those of Bhunia et al. [31], where shifts from $1643 \mathrm{~cm}^{-1}$ in the ligand to $1632 \mathrm{~cm}^{-1}$ in the respective complex were reported. The presence of the $\mathrm{OH}$ group in complexes 3 and 4 as depicted in Scheme 1 was deduced from the IR signals recorded at $2998 \mathrm{~cm}^{-1}$ and $2996 \mathrm{~cm}^{-1}$ respectively (Figures S5 and S6). This confirmed the absence of the deprotonation of the $\mathrm{O}-\mathrm{H}$ functionality. 


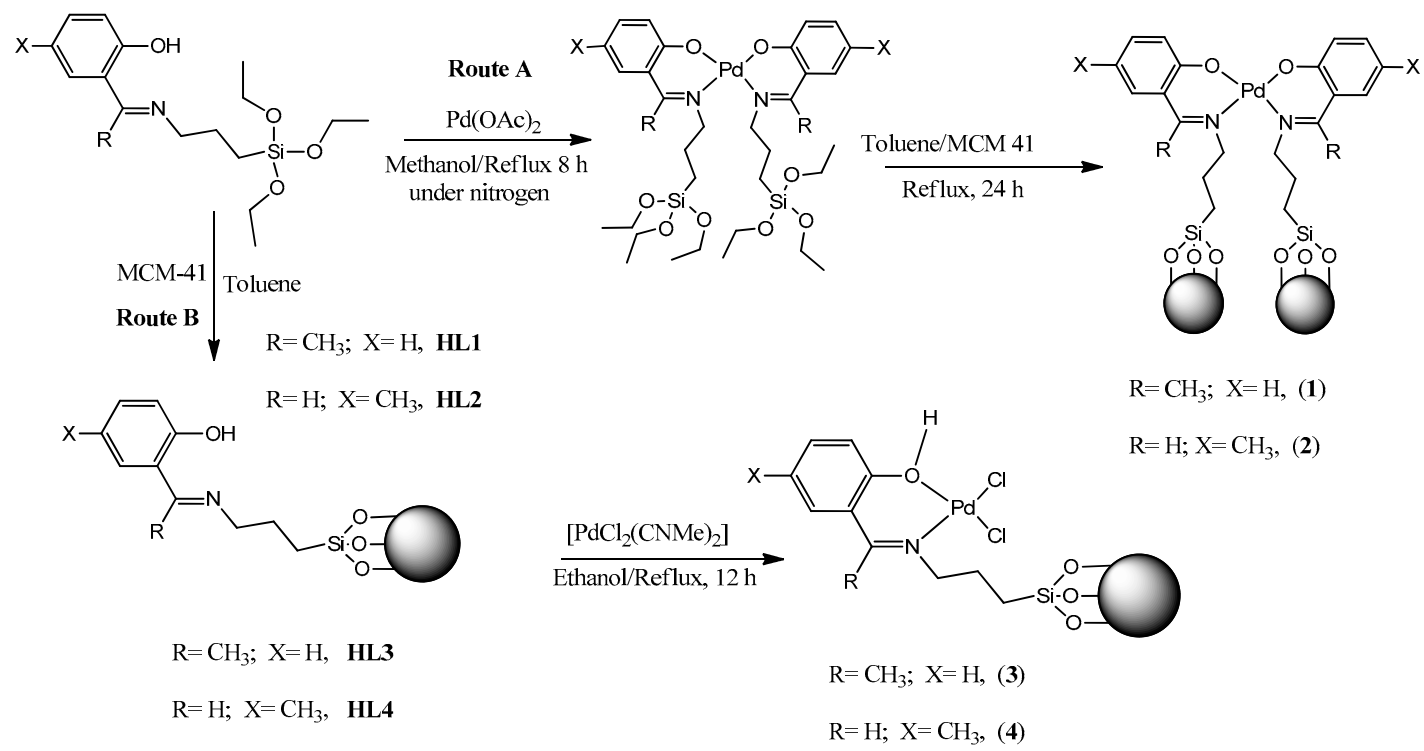

Scheme 1. The synthesis of the immobilized palladium complexes 1-4 via convergent (route A) and sequential (route B) routes.

Scanning Electron Microscopy (SEM) was used to determine the morphology and particle size of the immobilized ligands HL3 and HL4 and their respective complexes 1-4 (Figure 1, Figures S7 and S8). In general, the SEM images of the ligands and the respective complexes showed different morphologies and particle sizes. For example, the image of complex 4 exhibits spherical particles of diameters ranging from $1.163 \mu \mathrm{m}$ to $3.642 \mu \mathrm{m}$, while those of ligand HL4 displays quasi spherical shapes of diameters ranging from $0.985 \mu \mathrm{m}$ to $2.453 \mu \mathrm{m}$ (Figure 1). These particle sizes compare favourably with those reported by Polshettiwar and Molnár, ranging from hundreds of nanometres to micrometres [32]. The TEM images of complexes 1-4 also displayed morphologies with uniform particle sizes (Figure 1 and Figure S8). From the images, the mesoporous structures of the ligand were retained upon incorporation of the palladium metal, a confirmation that the palladium metal is immobilized on the pores of mesostructured silica MCM-41 [33].

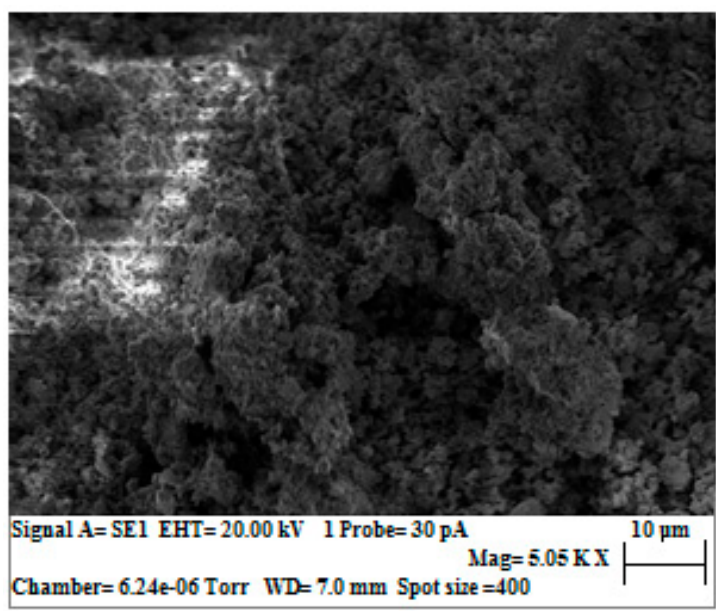

SEM: Ligand HL4

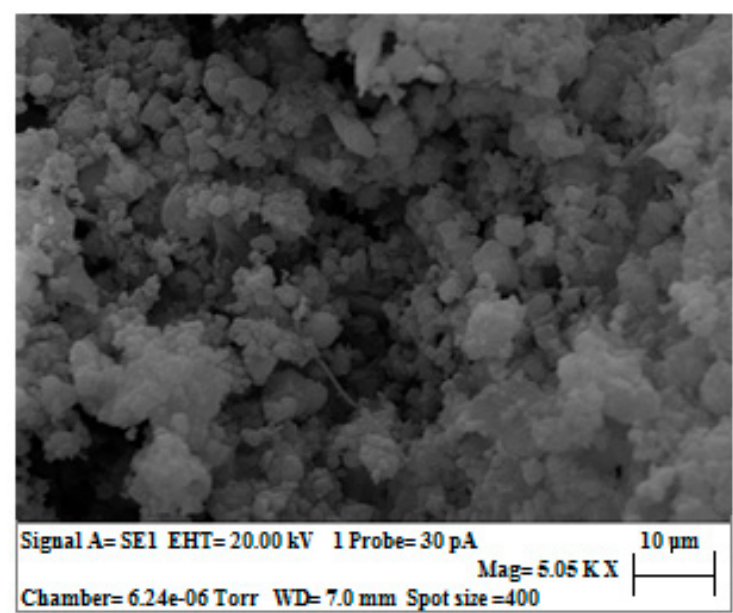

SEM: Complex 4

Figure 1. Cont. 


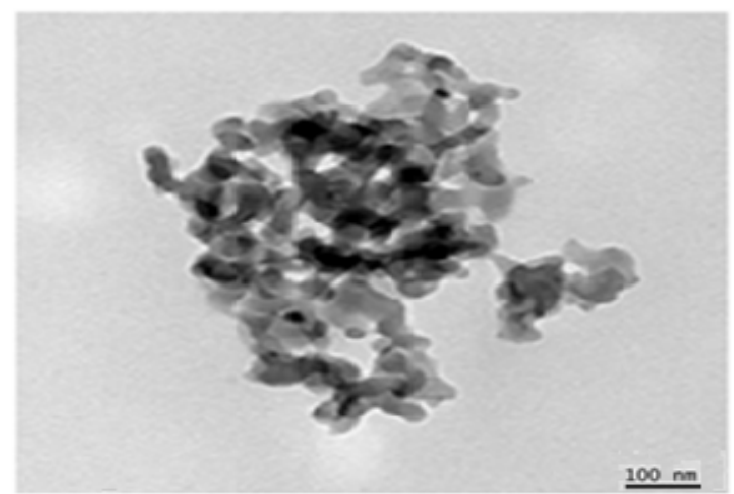

TEM: ligand HL4

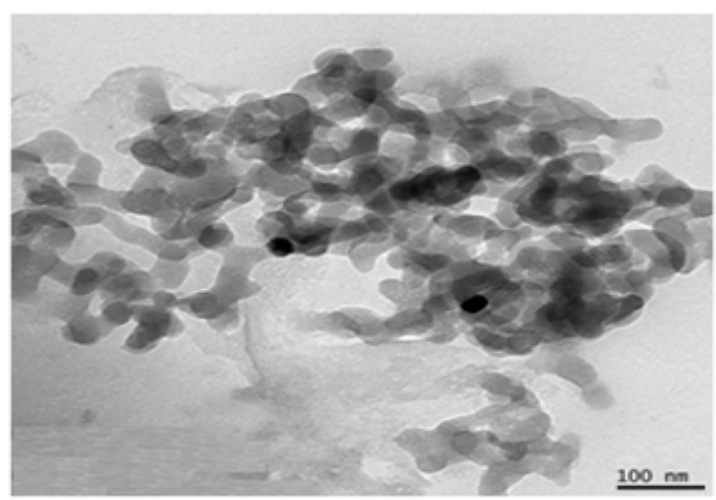

TEM: complex 4

Figure 1. The SEM and TEM images of ligand HL4 and the corresponding immobilized complex 4 showing different morphologies.

To investigate the qualitative elemental composition of complexes 1-4, the complexes were analysed using Energy Dispersive X-ray Spectroscopy (EDX) recorded at random surface points. EDX images of all complexes 1-4 showed the presence of palladium atoms, thus establishing successful complexation of the ligands (Figure S9 and Table S1). Thermogravimetric analysis (TGA) of the compounds was also used to study their thermal properties. The complexes exhibited similar decomposition patterns within a temperatue range from $50{ }^{\circ} \mathrm{C}$ to $800^{\circ} \mathrm{C}$ (Figure S10). For instance, complex 1 showed three phases of thermal behavior, with the intial weight loss occuring between $50{ }^{\circ} \mathrm{C}$ and $100^{\circ} \mathrm{C}$ attributed to the loss of moisture [34]. The second phase of decomposition occurred between $200{ }^{\circ} \mathrm{C}$ and $500{ }^{\circ} \mathrm{C}$ and may be associated with the loss of ligand HL1. The final phase $(60 \%)$ remained invariable up to $800{ }^{\circ} \mathrm{C}$ (Figure S9), signifying a high thermal stability of the palladium core (Table S2). Wide-angle powder XRD patterns for MCM-41 and the palladium complexes were obtained to establish their successful immobilization (Figure S15). The XRD spectrum of MCM-41 showed a broad peak between $2 \theta=20^{\circ}$ and $25^{\circ}$ which is characteristic of amorphous silica [35]. Upon immobilization of the complexes on silica, there was a notable decrease in the peak intensity, evidence that the MCM- 41 functionalization mainly occurred inside the mesopore channels [36]. For instance, complex 2 showed the presence of additional two peaks at $2 \theta=34.2^{\circ}$ and $52.0^{\circ}$ which corresponds to the palladium oxide planes PdO (101) and PdO (200) respectively (Figure S15). This behaviour further demonstrated that the structure of the MCM- 41 was unaltered, while the palladium core was preferentially located inside the silica pore.

\subsection{Catalytic Studies of the Immobilized Catalysts in the Methoxycarbonylation of Olefins}

\subsubsection{Methoxycarbonylation of 1-Hexene Catalysed by Complexes 1-4}

Catalytic studies of the immobilized complexes 1-4 in the methoxycarbonylation of 1-hexene were carried out at a CO pressure of $60 \mathrm{bar}$, at a temperature of $90^{\circ} \mathrm{C}$, at $0.5 \mathrm{~mol} \%$ palladium and with $p$-tolyl sulfonic acid (PTSA) as the acid promoter (Table 1). The major products formed as identified by GC and GC-MS were branched and linear 2-methylhexanoate and methyl heptanoate respectively (Figure S11). The role of the complex/ligand structure on the catalytic performance of the resultant catalysts was evaluated by comparing the catalytic activities of complexes $\mathbf{1 - 4}$. From Table 1 , it was evident that the bis(chelated) complexes $\mathbf{1}$ and $\mathbf{2}$ were more active than the mono(chelated) analogues 3 and 4. This is in good agreement with the results attained for the homogeneous systems [27] and was equally assigned to the improved stability of the bis(chelated) complexes 1 and 2 [37]. With respect to the effect of the ligand motif, there was no discernible variation in catalytic activities. For instance, complexes 1 and 2 bearing ligands HL3 and HL4, showed similar conversions of $76 \%$ and $78 \%$ respectively (Table 1, entries 1 and 2). This points to similar electronic and steric effects of the ligands on the metal coordination environment. Indeed, no appreciable effect on product regioselectivity was 
noted as all the complexes (1-4) showed preference to linear esters in the range of 60-63\% (Table 1, entries 1-4). To determine the role of the palladium complexes and phosphine additives in the methoxycarbonylation reactions, control experiments were carried out in the absence of the palladium complex or $\mathrm{PPh}_{3}$ (Table 1, entries 5 and 6). The absence of any catalytic activities established the role of the palladium complexes (Table 1, entry 5). In addition, the use of $\mathrm{Pd}(\mathrm{OAc})_{2} / \mathrm{PPh}_{3}$ recorded only $20 \%$ (Table 1, entry 7) in comparison to conversions of $61 \%$ to $78 \%$ obtained using complexes 1-4 (Table 1 , entries 1-4). The role of the phosphine additive is augmented by the lack of any catalytic activity when the reactions were performed without the addition of $\mathrm{PPh}_{3}$ (Table 1, entry 6). To date, there are very limited reports on the use of immobilized palladium catalysts in the methoxycarbonylation of olefins; however, there are a number of similar homogeneous palladium catalysts in literature. For instance, the 2-(diphenylphosphinoamino)pyridine palladium complexes reported by Aguirre et al. exhibited relatively higher TOFs of $28 \mathrm{~h}^{-1}$ in the methoxycarbonylation of 1-hexene [38] than values of $4.9 \mathrm{~h}^{-1}$ to $6.5 \mathrm{~h}^{-1}$ observed for our current complexes $1-4$. On the other hand, the palladium catalysts bearing benzimidazolylemethyl)amine, naphthyl(diphenyl)phosphines and mixed $\mathrm{N}^{\wedge} \mathrm{N}^{\wedge} \mathrm{X}(\mathrm{X}=\mathrm{O}$ and S) tridentate ligands afford comparable TOFs of $7.1 \mathrm{~h}^{-1}, 11 \mathrm{~h}^{-1}$ and $15 \mathrm{~h}^{-1}$ respectively to complexes 1-4 [39-41]. A rare example of immobilized palladium(II) catalysts supported on 2-vinyl-functional diphenyl-2 pyridylphosphine porous polymer displays exceptionally high TOFs of $2983 \mathrm{~h}^{-1}$ in the methoxycarbonylation of acetylene [42].

Table 1. The effect of catalyst structure and phosphines in the methoxycarbonylation of 1-hexene using complexes $1-4$ a.

\begin{tabular}{|c|c|c|c|c|}
\hline Entry & Catalyst & Conv $(\%)^{b}$ & $1 / b(\%)^{c}$ & TOF $^{d}$ \\
\hline 1 & 1 & 76 & $60 / 40$ & 6.3 \\
\hline 2 & 2 & 78 & $62 / 38$ & 6.5 \\
\hline 3 & 3 & 59 & $63 / 37$ & 4.9 \\
\hline 4 & 4 & 61 & $63 / 37$ & 5.0 \\
\hline $5^{e}$ & - & 0 & - & - \\
\hline $6^{\mathrm{f}}$ & 2 & 0 & 0 & 0 \\
\hline 7 & $\mathrm{Pd}(\mathrm{OAc})_{2} / \mathrm{PPh}_{3}$ & 20 & $65 / 35$ & 1.7 \\
\hline
\end{tabular}

a The reaction conditions: Pressure at 60 bar; temperature at $90^{\circ} \mathrm{C}$; time at $24 \mathrm{~h}$; the acid was $p$-tolyl sulfonic acid (PTSA); the solvents were methanol $50 \mathrm{~mL}$ and toluene $50 \mathrm{~mL}$; and Pd:PPh$: P T S A: 1-h e x e n e=1: 2: 10: 200$ where 1-hexene was $2 \mathrm{~mL}, 16.00 \mathrm{mmol} ; \mathrm{b} \%$ of 1-hexene converted to esters determined from GC assuming 100\% mass balance; ${ }^{c}$ Ratio between branched and linear ester; ${ }^{\mathrm{d}} \mathrm{TOF}\left(\mathrm{mol} . \mathrm{sub} / \mathrm{mol} . \mathrm{Pd} . \mathrm{h}^{-1}\right)$. ${ }^{\mathrm{e}}$ reaction without palladium complex; ${ }^{\mathrm{f}}$ reaction without $\mathrm{PPh}_{3}$.

\subsubsection{The Effect of Acid Promoter on the Methoxycarbonylation of 1-Hexene}

As opposed to the high catalytic activities reported for the $\mathrm{HCl}$ acid promoter for the homogeneous counterparts [27] and other palladium systems in our group [39,43,44], the immobilized complexes 1-4 gave no catalytic activity when $\mathrm{HCl}$ was used as the promoter (Figure 2). This is unusual and can be attributed to the hydrolysis of the $\mathrm{Si}-\mathrm{O}-\mathrm{Si}$ bonds through the protonation of the siloxane group [45]. In general, para-tolyl sulfonic acid (PTSA) gave the highest catalytic activity, followed by methyl sulfonic acid (MSA), while trimethyl aluminium (TMA) gave no catalytic activity (Figure 2). The trend established for the acid promoters, with the exception of $\mathrm{HCl}$, is concomitant with the strength and basicity of the respective acids [46]. However, the nature of the acid promoters did not have a notable influence on the regioselectivity of the esters (Figure 2) with the exception of TMA, which predominantly gave branched esters. This unique behaviour of the TMA with respect to product regioselectivity is unclear to us at this stage. 


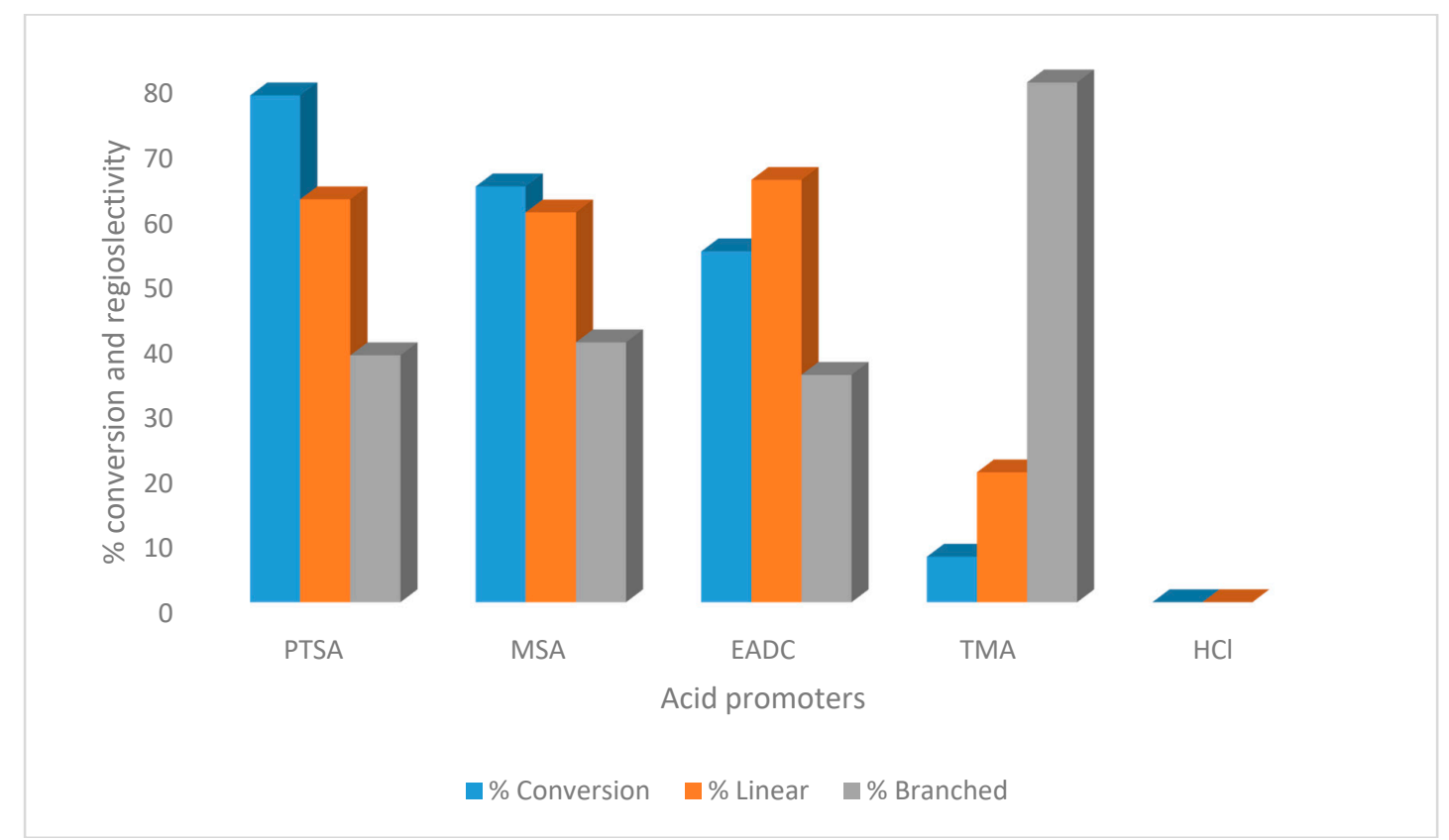

Figure 2. The effect of the acid promoters in the methoxycarbonylation of 1-hexene using complex 2 at a 1-hexene:HA: $\mathrm{PPh}_{3}: 2$ ratio of 200:10:2:1 and with 1-hexene $(2 \mathrm{~mL}, 16.00 \mathrm{mmol}), P_{\mathrm{CO}}, 60$ bar; temperature $90{ }^{\circ} \mathrm{C}$; time $24 \mathrm{~h}$; and the solvent as methanol/toluene $(100 \mathrm{~mL})$.

\subsubsection{The Effect of Reaction Conditions on Methoxycarbonylation Reactions}

In attempts to optimize the reaction conditions, the effect of the carbon monoxide pressure, the catalyst loading, the nature of the solvent and the reaction temperature were studied using complex 2. First, we observed that increasing the reaction temperature from $60{ }^{\circ} \mathrm{C}$ to $90^{\circ} \mathrm{C}$ resulted in increased percentage conversions from $59 \%$ to $78 \%$ (Table 2, entries 1 vs. 8 ). On the other hand, further increase of the reaction temperatures to $100{ }^{\circ} \mathrm{C}$ resulted in a drastic drop in the conversion to $51 \%$ (Table 2, entry 10). This can be largely attributed to the catalyst decomposition as evident by the mass of palladium black in the reactor. Reports by Mane et al. in the methoxycarbonylation of aryl iodides for silica immobilized palladium(II) catalysts give conversions $75 \%$ of $99 \%$ at reaction temperatures $75{ }^{\circ} \mathrm{C}$ and $100{ }^{\circ} \mathrm{C}$ respectively. Similarly, the CO pressure was found to significantly affect the catalytic activities of complex 2. For example, an increase in pressure from 40 bar to 60 was marked by a concomitant increase in percentage conversion from $66 \%$ to $78 \%$ (Table 2, entries 1 vs. 7 ). This was expected and is believed to originate from a higher rate of $\mathrm{CO}$ insertion into the Pd-alkyl bonds at higher CO pressures [47].

The stability of complex 2 was also studied by varying the reaction time from $12 \mathrm{~h}$ to $36 \mathrm{~h}$ (Table 2, entries 1, 6 and 9). From the plot given in Figure S12, catalyst 2 showed two phases of catalytic activities with an optimum at $24 \mathrm{~h}\left(\mathrm{TOF}=6.5 \mathrm{~h}^{-1}\right)$. The first phase, between $0-24 \mathrm{~h}$ is thus consistent with an activation process (TOF $=5.4 \mathrm{~h}^{-1}$ after $12 \mathrm{~h}$ ), while the second phase between $24 \mathrm{~h}$ to $36 \mathrm{~h}$ is typical of a catalyst deactivation (TOF $=5.0 \mathrm{~h}^{-1}$ ). This observation mirrors those previously observed in the methoxycarbonylation of 4-bromoacetopehenone, where optimum catalytic activity was obtained within $14 \mathrm{~h}$, followed by a drop in the activity between $14 \mathrm{~h}$ to $24 \mathrm{~h} \mathrm{[48].} \mathrm{With} \mathrm{respect} \mathrm{to} \mathrm{product}$ distribution, an increase in the reaction time from $12 \mathrm{~h}$ to 36 was followed by a slight increase in the composition of the branched esters from $34 \%$ and $40 \%$ respectively (Table 2, entries 1 and 9). The trend could be assigned to the isomerization of 1-hexene with time to form internal hexenes prior to methoxycarbonylation [49]. 
Table 2. The effect of the reaction conditions in the methoxycarbonylation of 1-hexene using complex 2 .

\begin{tabular}{cccccccc}
\hline Entry & $\boldsymbol{P}_{\mathbf{C O}}(\mathbf{b a r})$ & $\left.\operatorname{Temp}^{\circ}{ }^{\circ} \mathbf{C}\right)$ & Time $(\mathbf{h})$ & $\mathbf{P d} \%$ & Conv $_{(\%)} \mathbf{b}$ & $\mathbf{1 / b}(\%)$ & TOF $^{\mathbf{d}}$ \\
\hline 1 & 60 & 90 & 24 & 0.5 & 78 & $62 / 38$ & 6.5 \\
2 & 60 & 90 & 24 & 0.25 & 27 & $64 / 36$ & 4.5 \\
3 & 60 & 90 & 24 & 0.75 & 94 & $65 / 35$ & 5.2 \\
4 & 60 & 90 & 24 & 1.0 & 87 & $62 / 38$ & 3.6 \\
5 & 60 & 90 & 24 & 1.5 & 62 & $61 / 39$ & 1.7 \\
6 & 60 & 90 & 12 & 0.5 & 34 & $66 / 34$ & 5.4 \\
7 & 40 & 90 & 24 & 0.5 & 66 & $64 / 36$ & 5.5 \\
8 & 60 & 60 & 24 & 0.5 & 59 & $61 / 39$ & 4.9 \\
9 & 60 & 90 & 36 & 0.5 & 90 & $60 / 40$ & 5.0 \\
10 & 60 & 100 & 24 & 0.5 & 51 & $63 / 37$ & 4.3 \\
\hline
\end{tabular}

a Reaction conditions: 1-hexene (2 mL, 16.00mmol); 1-hexene:HCl: $\mathrm{PPh}_{3} ; 100: 5: 1 .{ }^{\mathrm{b}}$ The $\%$ of 1-hexene converted to esters determined from GC, assuming $100 \%$ mass balance; ${ }^{\mathrm{c}}$ The molar ratio between branched and linear esters. d TOF (mol. sub/mol. $\mathrm{Pd} \mathrm{h}^{-1}$ ).

The effect of the catalyst loading was also investigated to ascertain the optimum catalyst concentration required for the methoxycarbonylation of 1-hexene using complex 2 . We noted that increasing the palladium loading from $0.5 \mathrm{~mol} \%$ to $1.5 \mathrm{~mol} \%$ was followed by a drastic decrease in TOF from $6.5 \mathrm{~h}^{-1}$ to $1.7 \mathrm{~h}^{-1}$ respectively (Figure S13). Such an observation could be due to the formation of palladium clusters at higher loadings, with the net effect of limiting the catalyst accessibility by the olefin substrate [50]. On the other hand, a lower loading of $0.25 \mathrm{~mol} \%$ gave a lower TOF of $4.5 \mathrm{~h}^{-1}$, possibly due to a lower concentration of the active species. Thus, a catalyst loading of $0.5 \mathrm{~mol} \%$ was obtained as the optimum value (Table 2 entries $1-5$ ).

The influence of different solvent systems on the methoxycarbonylation of 1-hexene using complex 2 was also studied (Figure 3). From the results, it was clear that the catalytic activity of complex 2 was dependent on the polarity of the solvent mixture. For instance, while the more polar mixture of chlorobenzene/methanol gave lower conversions of 36\%, the less polar toluene/methanol system exhibited higher conversions of $78 \%$ (Figure 3). This trend is supported by the findings that catalytic activities in methoxycarbonylation reactions are controlled by the dielectric constants of the solvents employed [51]. Indeed, a mixture of the dimethyl formamide (DMF)/methanol solvent system afforded no catalytic activity due to a far much higher dielectric constant [52] in addition to the strong coordinating ability of DMF [53]. 


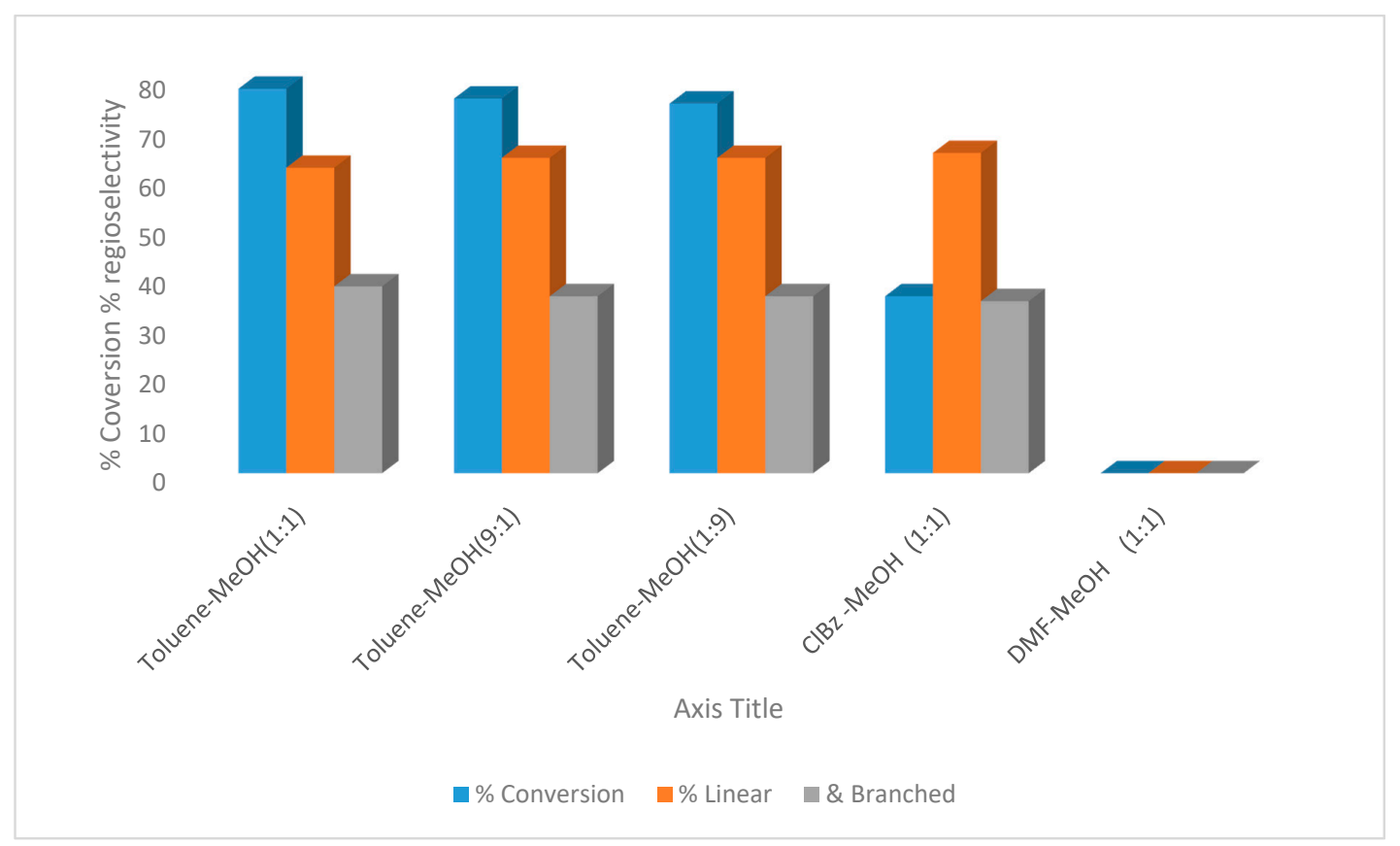

Figure 3. The effect of solvent mixtures in the methoxycarbonylation of 1-hexene. The reaction conditions were time, $24 \mathrm{~h}$; $P_{\mathrm{CO}}: 60 \mathrm{bar}$; temperature, $90{ }^{\circ} \mathrm{C}$; solvent, methanol/toluene $(100 \mathrm{~mL})$ complex $2(0.5 \% \mathrm{~mol})$; and $\mathrm{PPh}_{3}: \mathrm{PTSA}: 1$-hexene ratio, 1:5:100.

\subsubsection{Catalyst Recycling and Leaching Studies}

The main aim of this current study was to design recoverable catalysts in the methoxycarbonylation of olefins. As noted in the introduction, this has a lot of potential, owing to the appeal of the ester products in the fragrance and detergent industries. We, thus, studied the recyclability of the immobilized catalysts (1-4) in the methoxycarbonylation of 1-hexene under the optimized reaction conditions of $90^{\circ} \mathrm{C}, 60 \mathrm{bar}$ and reaction time of $24 \mathrm{~h}$ and with toluene/methanol as the solvent mixture (ratio 1:1) and PTSA as the acid promoter. Figure 4 shows the data for the recycling experiments of four runs for each complex. The data in Figure 4 showed that all the catalysts maintained significant catalytic activities even in the fourth cycle. Consistent with the expected stability trends, the bis(chelated) complexes $\mathbf{1}$ and $\mathbf{2}$ showed minimal drops in percentage conversions (1st and 4 th runs) of $7 \%$ and $8 \%$ respectively, while the mono(chelated) analogues, 3 and 4 , showed relatively larger drops of $18 \%$ and $15 \%$ respectively. In comparison to the recycling efficiencies reported in similar immobilized systems, palladium catalysts supported on N-doped carbon nanotubes displayed conversions of $98 \%$ and $25 \%$ in the first and fourth runs respectively in the methoxycarbonylation of iodobenzene [52]. This represents a significant drop in the fourth run (lower stability) when compared to, for instance, complex 2 , which recorded conversions of $78 \%$ and $72 \%$ in the first and fourth runs respectively. In another study, silica supported palladium complexes reported by Mane et al. showed a better performance, giving percentage conversions of $99 \%$ and $95 \%$ within $3 \mathrm{~h}$ in the first and fifth runs respectively in the methoxycarbonylation of iodobenzene [24]. 


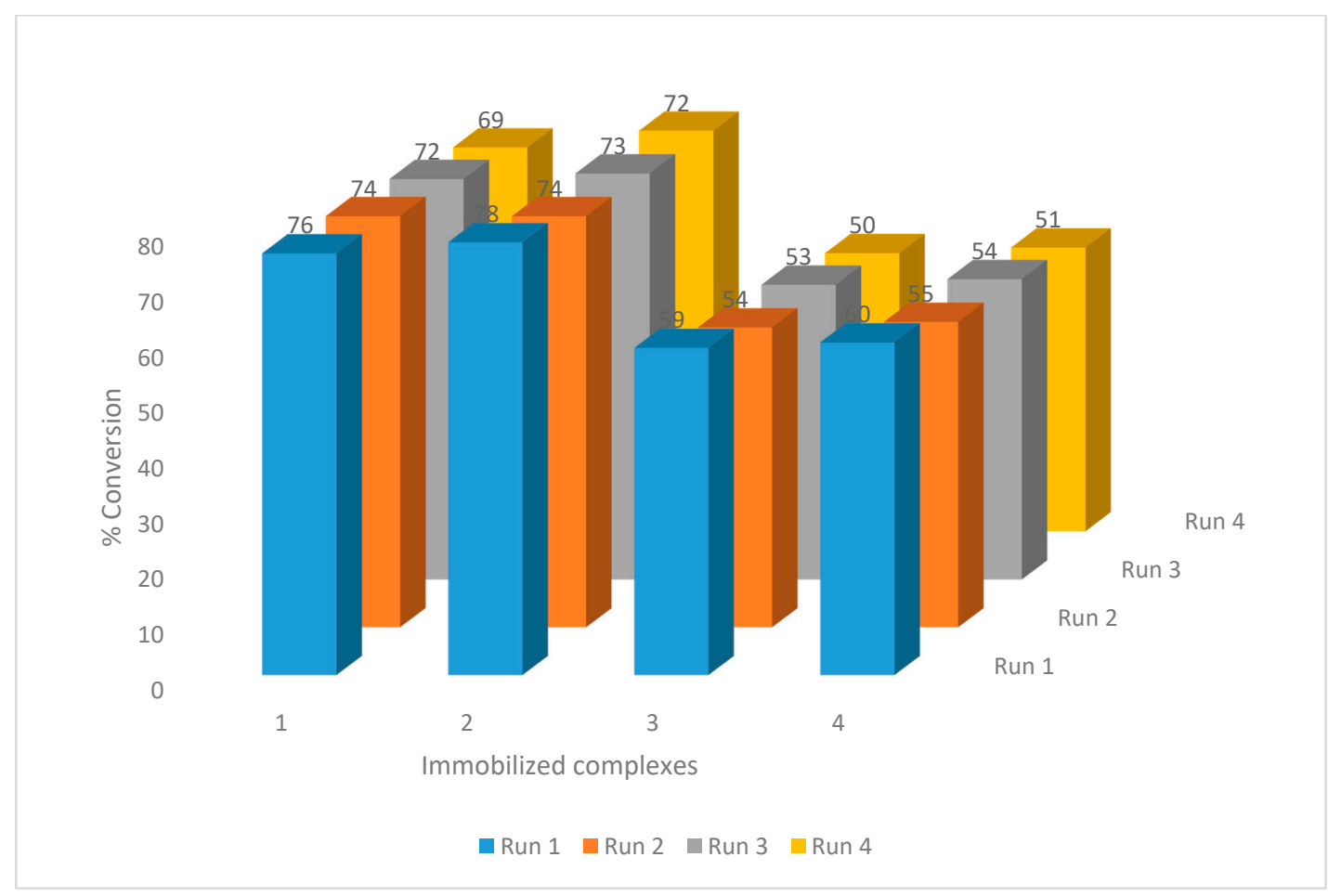

Figure 4. A graph showing the catalytic activities of complexes 1-4 and their recycling. Reaction conditions were time, $24 \mathrm{~h}$; $P_{\mathrm{CO}}: 60$ bar; temperature, $90{ }^{\circ} \mathrm{C}$; solvent, methanol/toluene $(100 \mathrm{~mL})$ complex 1-4; Pd:PPh $:$ PTSA:1-hexene ratio of 1:2:10:200; and 1-hexene (2 mL, $16.00 \mathrm{mmol})$.

In order to gain an in depth understanding of the reasons behind the slight reductions in the catalytic activities of the complexes 1-4 in subsequent cycles, a hot filtration test was done using catalyst 2 . This was to ascertain if leaching of the active species may be implicated in the reductions in percentage conversions in subsequent runs. Thus, after $12 \mathrm{~h}$ of the initial reaction (38\%) with complex 2, the mixture was filtered and the resultant filtrate was subjected to a $\mathrm{CO}$ pressure of $60 \mathrm{bar}$ at a temperature of $90^{\circ} \mathrm{C}$ for an additional $12 \mathrm{~h}$. The percentage conversion remained largely constant $(39 \%)$ as depicted in Figure 5. This lack of catalytic activity of the filtrate clearly ruled out leaching as the possible cause of the loss of catalytic activity. It is, therefore, reasonable to assign other factors such as catalyst abrasion and change in morphology to be responsible for the observed drop in catalytic activities [52]. In an attempt to resolve the true nature of the active species (heterogeneous vs. homogeneous), a mercury drop test was conducted using complex 2 (Figure 5). Upon addition of a few drops of mercury at the beginning of the reaction, we observed a significant decline in the percentage conversion from $78 \%$ to $47 \%$, consistent with the heterogeneous nature of the active species [54]. 


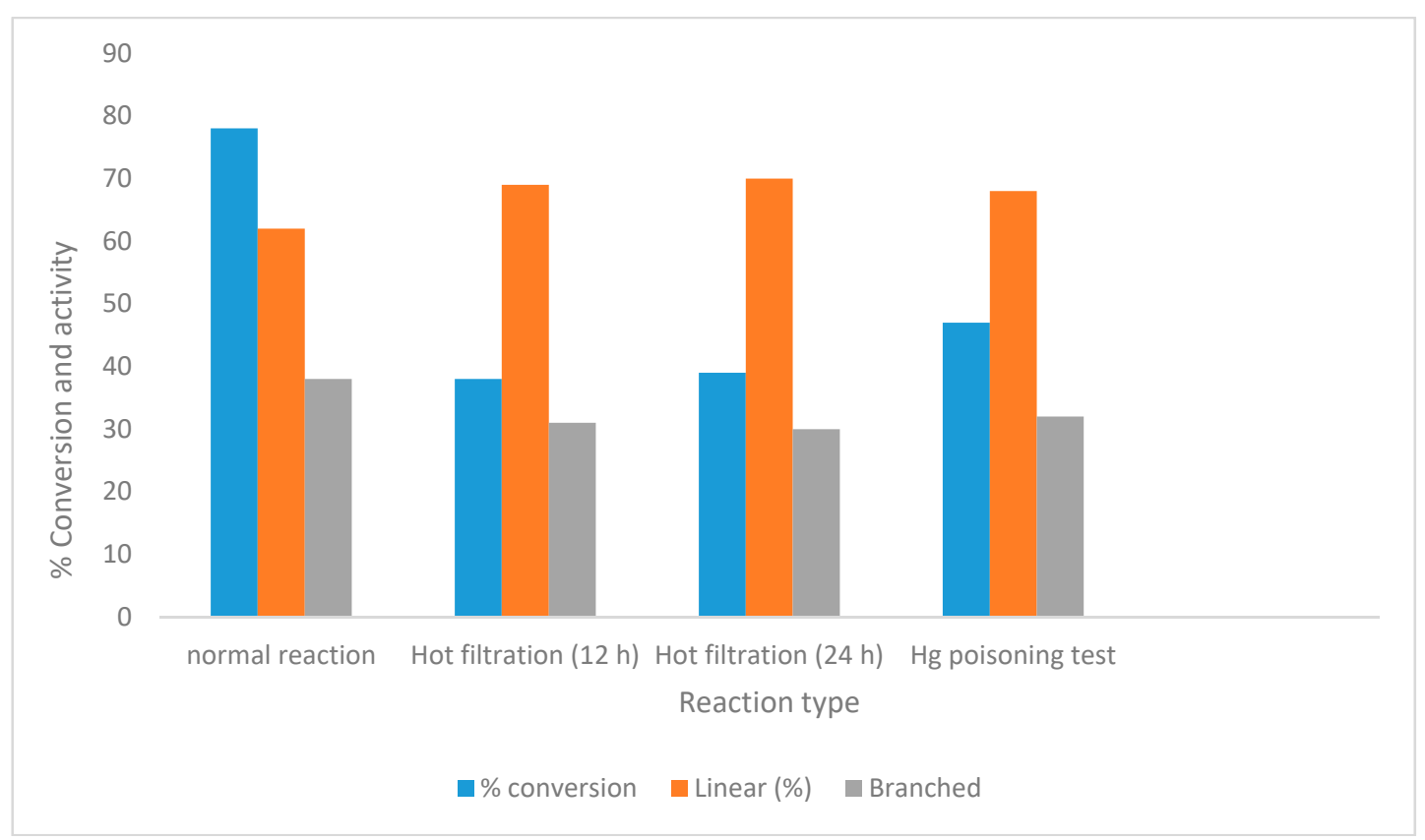

Figure 5. A graph showing the comparison between the control reaction, hot filtration and mercury poisoning experiments.

Lastly, we analysed the spent catalyst from complex 2 using TEM and SEM-EDX to determine any changes in morphology and the palladium metal content. Figure 6 shows a comparison of the SEM and TEM images of the fresh and spent catalysts of complex 2. The TEM images of the fresh and used catalysts confirmed slight changes in morphology. For example, the images of complex 2 and the corresponding used catalyst showed that the ordered mesoporous structure was partially destroyed after four runs (Figure 6). In addition, the EDX data showed a reduction of the palladium content in all the complexes (Table S3), pointing to a possible abrasion of the catalyst in subsequent cycles [55]. Thus, it is conceivable to conclude that the slight drops in catalytic activities observed in the recycling experiments is due to changes in the physical properties of the active species. It is noteworthy to mention that the product regioselectivity did not change appreciably in the subsequent runs, indicating that the identity of the active species remained largely invariant.

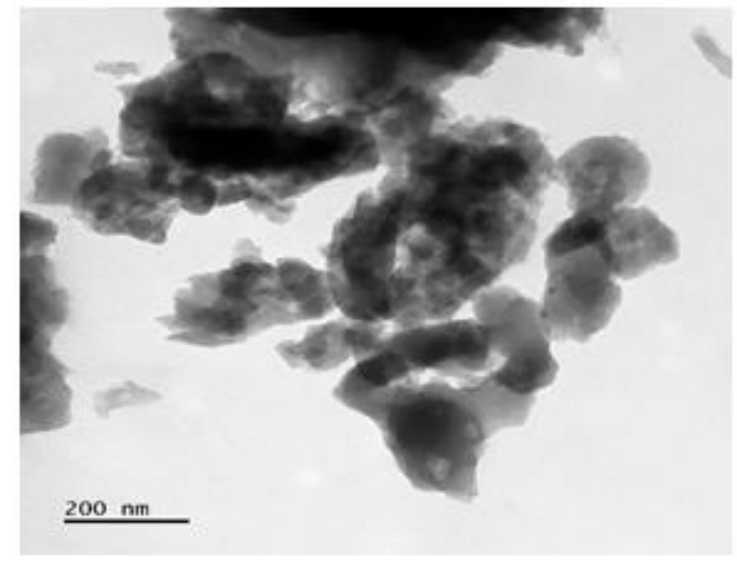

TEM (Fresh atalyst)

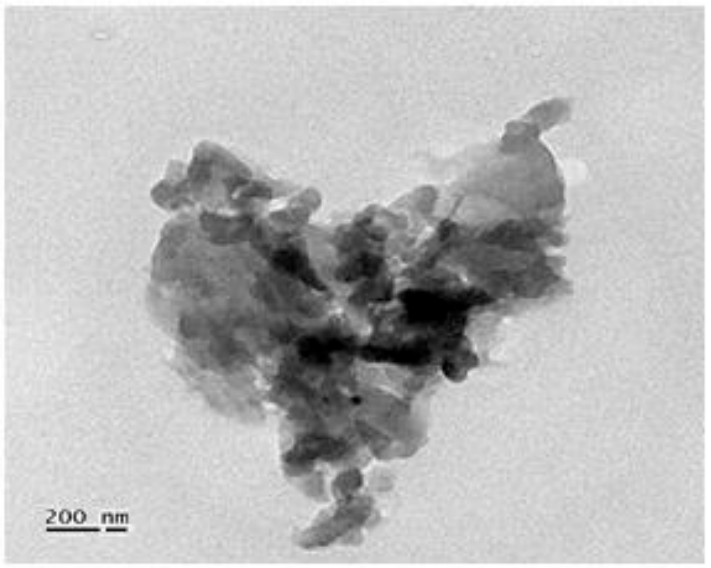

TEM (Used catalyst)

Figure 6. Cont. 


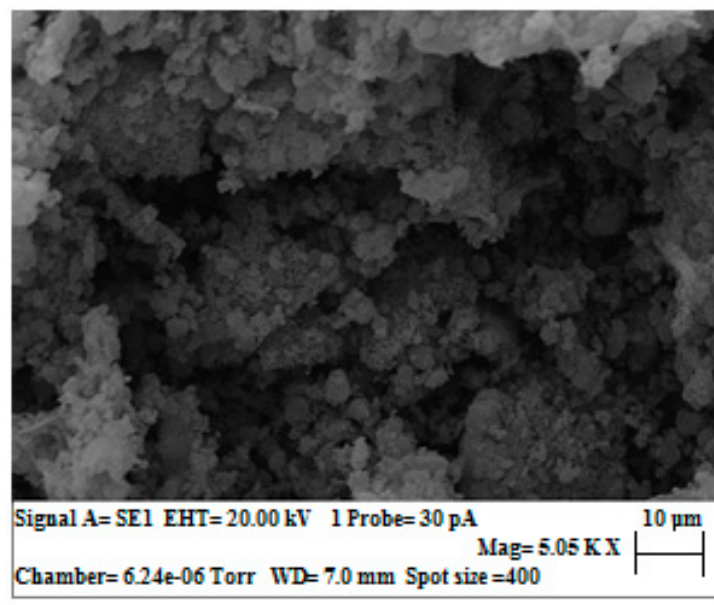

SEM (Fresh catalyst)

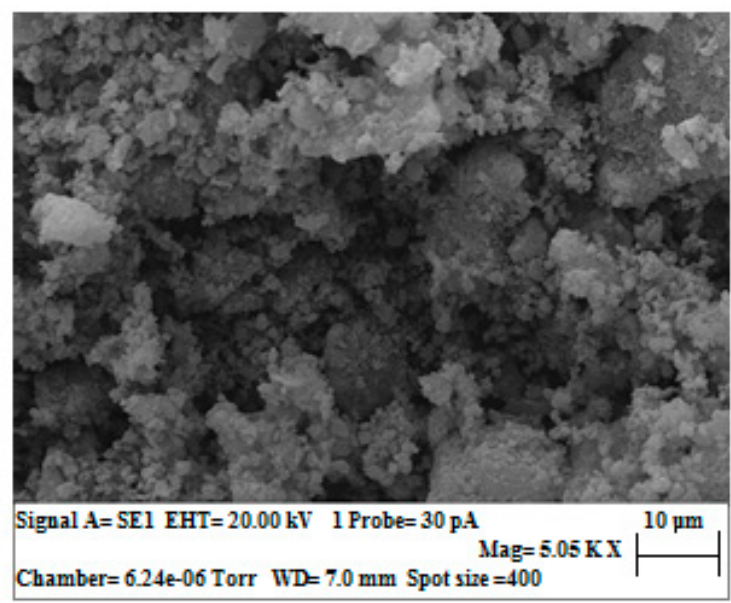

SEM (Used catalyst)

Figure 6. The TEM and SEM images of the fresh and spent catalysts obtained from complex 2.

\section{Experimental Section and Methods}

\subsection{General Instrumentation and Materials}

All solvents were purchased from Merck, dried and distilled following standard protocols before use. Toluene was dried over sodium wire and benzophenone, while methanol was dried by heating over magnesium activated with iodine [56]. Dichloromethane was dried over phosphorus pentoxide under nitrogen and stored in molecular sieves before use, and chlorobenzene was dried over phosphorus pentoxide [56]. DMF was dried over calcium hydride [57]. The reagents, palladium dichloride (59\%), palladium(II) acetate (98\%), 1-hexene, hydrochloric acid, $\mathrm{p}-\mathrm{TsOH}(\geq 98.5 \%), \mathrm{PPh}_{3}(99 \%)$, diphenyl phosphine ethane, dppe, $(98 \%), \mathrm{P}(\mathrm{Cy})_{3}$ $(98 \%)$, EADC $(97 \%)$ and MCM-41, were purchased from Sigma-Aldrich and used as received without further purification. Ligands 2-phenyl-2-((3-(triethoxysilyl)propyl)imino)ethanol (HL1) and 4-methyl-2-(((3-(triethoxysilyl)propyl)imino)methyl)phenol (HL2) and the respective palladium complexes $\operatorname{Pd}(\mathbf{L} 1)_{2}$ and $\operatorname{Pd}(\mathbf{L} 2)_{2}$ were synthesised according to our reported procedures [27]. The infrared spectra were recorded on a Perkin-Elmer Spectrum 100 in the $4000-400 \mathrm{~cm}^{-1}$ range. The TEM images were taken using a transmission electron microscope (JEOL JEM, 1400 model, Peabody., MA, USA) operating at $200 \mathrm{kV}$ accelerating voltage. All the samples were sonicated in ethanol and placed on carbon-coated copper grids. The morphology and particles sizes of the immobilized compounds were studied using scanning electron microscope of the ZEISS EVO LS15 (Thornwood, NY, USA) model operating at an accelerating voltage of $20 \mathrm{kV}$ while the elemental contents of the immobilized complexes were analysed using an Oxford make EDX detector. The thermogravimetric analysis was carried out on a thermogravimetric analyser (TGA 4000 model, Boston, MA, USA) using 5-12 mg samples placed on a ceramic pan and heated within the temperature range of $50-800{ }^{\circ} \mathrm{C}$ at a $40^{\circ} \mathrm{C} / \mathrm{min}$ heating rate under nitrogen flow. GC and GC-MS analyses was performed on a Varian CP-3800 and QP2010 respectively.

\subsection{Synthesis of (Phenoxy)Imine Immobilized Ligands and Their Palladium(II) Complexes}

\subsubsection{Synthesis of HL1-MCM-41 (HL3)}

To a suspension of MCM-41 (0.25 g) in toluene (50 mL), compound HL1 $(0.50 \mathrm{~g}, 1.47 \mathrm{mmol})$ was added and the mixture was sonicated for $25 \mathrm{~min}$. The reaction mixture was then heated at $90{ }^{\circ} \mathrm{C}$ for a further $14 \mathrm{~h}$. After the reaction period, the crude product was filtered, and the resulting precipitate was washed with ethanol and toluene to give a yellow precipitate, which was then dried in an oven for 
$12 \mathrm{~h}$ at $110{ }^{\circ} \mathrm{C}$ to give $\mathrm{HL} 3$ as a yellow powder: Yield $=0.61 \mathrm{~g}(81 \%) ; \mathrm{IR} v_{\max } / \mathrm{cm}^{-1}$ were $v_{(\mathrm{OH})}=2944$, $v_{(\mathrm{C}=\mathrm{N})}=1614$ and $v_{(\mathrm{Si}-\mathrm{O}-\mathrm{Si})}=1061$.

\subsubsection{Synthesis of HL2-MCM 41 (HL4)}

Compound HL4 was synthesised following the procedure reported for HL3 by using MCM-41 $(0.20 \mathrm{~g})$ and HL2 $(0.40 \mathrm{~g}, 1.18 \mathrm{mmol})$ : Yield $=0.47 \mathrm{~g}(78 \%) ; \mathrm{IR} v_{\max } / \mathrm{cm}^{-1}$ were $v_{(\mathrm{OH})}=3072$, $v_{(\mathrm{C}=\mathrm{N})}=1611, v_{(\mathrm{C}=\mathrm{C})}=1547$ and $v_{(\mathrm{Si}-\mathrm{O}-\mathrm{Si})}=1031$.

\subsubsection{Synthesis of $\left(\operatorname{Pd}(\mathbf{L 1})_{2}\right)-\mathrm{MCM}-41(\mathbf{1})$}

A solution of $\mathrm{Pd}(\mathrm{L} 1)_{2}(0.15 \mathrm{~g}, 0.19 \mathrm{mmol})$ in toluene $(10 \mathrm{~mL})$ was added to a solution of MCM-41 $(1.35 \mathrm{~g})$ in toluene $(10 \mathrm{~mL})$. The mixture was then refluxed for $24 \mathrm{~h}$ to give a yellow mixture. The crude solid was filtered off and then washed with dichloromethane to remove any unreacted material. The resulting yellow product was dried under vacuum to give a light-yellow powder: Yield $=1.34 \mathrm{~g}$ $(89 \%) ; \mathrm{IR} v_{\max } / \mathrm{cm}^{-1}$ were $v_{(\mathrm{C}=\mathrm{N})}=1648$ and $v_{(\mathrm{Si}-\mathrm{O}-\mathrm{Si})}=1055$.

\subsubsection{Synthesis of $\left(\operatorname{Pd}(\mathbf{L} 2)_{2}\right)-M C M-41(2)$}

Complex 2 was synthesised by following the same procedure as complex 1 using complex $\operatorname{Pd}(\mathbf{L} 2)_{2}$ $(0.15 \mathrm{~g}, 0.19 \mathrm{mmol})$ and MCM-41 (1.35 g): Yellow solid; yield $=1.32 \mathrm{~g}(88 \%) ; \mathrm{IR} v_{\max } / \mathrm{cm}^{-1}$ was $v_{(\mathrm{C}=\mathrm{N})}$ $=1625$ and $v_{(\mathrm{Si}-\mathrm{O}-\mathrm{Si})}=1054$.

\subsubsection{Synthesis of $\mathrm{Pd}(\mathrm{HL} 3)\left(\mathrm{Cl}_{2}\right)(3)$}

To a solution of $\mathrm{PdCl}_{2}(\mathrm{NCMe})_{2}(0.10 \mathrm{~g}, 0.39 \mathrm{mmol})$ in ethanol $(20 \mathrm{~mL})$, HL3 $(0.10 \mathrm{~g})$ was added and refluxed for $12 \mathrm{~h}$. The brown precipitate obtained was washed with ethanol followed by dichloromethane and dried in an oven at $110^{\circ} \mathrm{C}$ to give complex 3 as a reddish brown solid: Yield $=0.13$ $\mathrm{g}(65 \%) ; \mathrm{IR} v_{\max } / \mathrm{cm}^{-1}$ were $v_{(\mathrm{OH})}=2998, v_{(\mathrm{C}=\mathrm{N})}=1622, v_{(\mathrm{C}=\mathrm{C})}=1536$ and $v_{(\mathrm{Si}-\mathrm{O}-\mathrm{Si})}=1055$

\subsubsection{Synthesis of $\mathrm{Pd}(\mathrm{HL} 4)\left(\mathrm{Cl}_{2}\right)(4)$}

Complex 4 was synthesised following the same procedure as 3 by using $\mathrm{PdCl}_{2}(\mathrm{NCMe})_{2}(0.10 \mathrm{~g}$, $0.39 \mathrm{mmol})$ and HL4 $(0.10 \mathrm{~g})$ : Reddish brown solid; yield $=0.14 \mathrm{~g}(70 \%) ; \mathrm{IR} v_{\max } / \mathrm{cm}^{-1}$ were $v_{(\mathrm{OH})}=2996, v_{(\mathrm{C}=\mathrm{N})}=1652, v_{(\mathrm{C}=\mathrm{C})}=1547$ and $v_{(\mathrm{Si}-\mathrm{O}-\mathrm{Si})}=1058$.

\subsection{General Procedure for the Methoxycarbonylation Reactions}

The methoxycarbonylation catalytic reactions were carried out in a stainless-steel autoclave Parr reactor equipped with a temperature/pressure control unit, an internal cooling system and a sampling valve. In a typical experiment, complex $1(0.5 \% \mathrm{~mol} \mathrm{Pd}), p$ - $\mathrm{TsOH}(0.14 \mathrm{~g})$, 1-hexene $(2 \mathrm{~mL}, 16.00 \mathrm{mmol})$ and $\mathrm{PPh}_{3}(0.04 \mathrm{~g}, 0.16 \mathrm{mmol})$ in a Schlenk tube were added toluene $(50 \mathrm{~mL})$ and methanol $(50 \mathrm{~mL})$. The mixture was then introduced into the reactor, purged three times with $\mathrm{CO}$ and set at the required temperature and pressure, and then, the reaction was stirred at $500 \mathrm{rpm}$. At the end of the reaction time, the reactor was cooled to room temperature and the excess $\mathrm{CO}$ vented off. Samples were drawn and filtered using micro-filter prior to the GC analysis to determine the percentage conversion of the substrate to the products, assuming 100\% mass balance. GC-MS was used to determine the identity of the ester products, while the linear and branched esters were assigned using standard authentic samples. The GC analyses was carried out under the following conditions of $25 \mathrm{~m}(1.2 \mathrm{~mm}$ film thickness) CP-Sil 19 capillary column; injector temperature $250{ }^{\circ} \mathrm{C}$; oven program $50{ }^{\circ} \mathrm{C}$ for $4 \mathrm{~min}$, rising to $200{ }^{\circ} \mathrm{C}$ at $20^{\circ} \mathrm{C} / \mathrm{min}$ and holding at $200{ }^{\circ} \mathrm{C}$ for $30 \mathrm{~min}$; and nitrogen carrier column gas 5 psi.

\subsection{General Procedure for Catalyst Recycling}

The catalyst recycling experiments for all the four complexes were performed by centrifuging the initial reaction mixture at $8500 \mathrm{rpm}$ for $10 \mathrm{~min}$ at the end of the preceding reaction. The supernatant 
liquid was then carefully decanted to leave the solid catalyst which was then reintroduced into the reactor, and the required amount of solvent added. This was followed by the addition of the 1-hexene substrate, acid promoter and $\mathrm{PPh}_{3}$ stabilizer. The reaction was then run at the set conditions of $60 \mathrm{bar}$ of $\mathrm{CO}$ and $90^{\circ} \mathrm{C}$ for $24 \mathrm{~h}$. The analyses and quantification of the reaction mixture were carried out by GC and GC-MS as outlined in Section 3.3.

\section{Conclusions}

In conclusion, we have successfully synthesized and characterized four palladium complexes of (phenoxy)imine ligands immobilized on mesoporous MCM-41 silica. Structural characterization of the complexes has been achieved using FT-IR, SEM-EDX, TEM, TGA and XRD techniques. All the complexes formed active catalysts in the methoxycarbonylation of 1-hexene to give predominantly linear esters. The catalytic activities of the complexes were controlled by the coordination environment around the palladium. The immobilized complexes were recycled up to four times without appreciable loss in the catalytic activity. Changes in the physical state and morphology of the active species may account for a slight loss in the catalytic activity in the recycling experiments. Hot filtration tests established the absence of any leaching, while mercury drop experiments pointed to a largely heterogeneous nature of the active systems.

Supplementary Materials: The following are available online at http:/ /www.mdpi.com/2073-4344/9/2/143/s1, Figure S1: The IR spectrum of ligand HL3 showing $v_{(\mathrm{C}=\mathrm{N})}$ at 1614 and $v_{(\mathrm{Si}-\mathrm{O}-\mathrm{Si})}$ at 1061, Figure S2: The IR spectrum of ligand HL4 showing $v_{(\mathrm{C}=\mathrm{N})}$ at 1611 and $v_{(\mathrm{Si}-\mathrm{O}-\mathrm{Si})}$ at 1031, Figure S3: The IR spectrum of complex 1 showing $v_{(\mathrm{C}=\mathrm{N})}$ at 1648 and $v_{(\mathrm{Si}-\mathrm{O}-\mathrm{Si})}$ at 1055, Figure S4: The IR spectrum of complex 2 showing $v_{(\mathrm{C}=\mathrm{N})}$ at 1625 and $v_{(\mathrm{Si}-\mathrm{O}-\mathrm{Si})}$ at 10, Figure S5: The IR spectrum of complex 3 showing $v_{(\mathrm{C}=\mathrm{N})}$ at 1622 and $v_{(\mathrm{Si}-\mathrm{O}-\mathrm{Si})}$ at 1055 , Figure S6: The IR spectrum of complex 4 showing $v_{(\mathrm{C}=\mathrm{N})}$ at 1652 and $v_{(\mathrm{Si}-\mathrm{O}-\mathrm{Si})}$ at 1058, Figure S7: SEM images displaying the morphologies of the immobilized ligands and complexes 1-4, Figure S8: TEM images displaying the morphologies of the Immobilized ligands and their respective complexes , Figure S9: The Energy Dispersive X-ray Spectroscopy (EDX) spectrum of ligand L4 and complex 4 showing the presence of a Pd signal in 4, Figure S10: A TGA graphical plot showing the decomposition phases of complexes 1-4, Figure S11: The GC and GC-Ms spectra of methoxycarbonylation products identified as branched (methyl 2-methylhexanoate) and linear (methyl heptanoate) esters, Figure S12: A graphical plot showing the variations of TOF and the \% conversion with the reaction time for complex 2, Figure S13: A graphical plot showing the variations of TOF and the \% conversion with the catalyst concentration for complex 2, Figure S14: TEM images showing changes in the morphologies of the immobilized catalyst after four cycles of catalysis experiments, Figure S15: XRD patterns for the native MCM-41 (A) and complex 2 (B). Table S1: The EDX data for the fresh immobilized complexes showing elemental compositions, Table S2: The residual masses of the complexes after heating to $800{ }^{\circ} \mathrm{C}$, Table S3: The EDX data for the recycled immobilized complexes showing elemental compositions.

Author Contributions: S.O.A.: The synthesis, characterization and catalysis experiments and the initial drafting of the manuscript. S.O.O.: The conception of the project, manuscript corrections and preparation of the final draft for submission.

Funding: This research was funded by South African NRF-DST Center of Excellence in Catalysis, $\left(c^{*}\right.$ change, OLE10.3-UKZN) and NRF (SA) competitive program for rated researchers (grant number: CPRR 98938) The APC was funded by University of KwaZulu-Natal.

Acknowledgments: The authors greatly appreciate NRF-DST (South Africa) and the University of KwaZulu-Natal for financial support.

Conflicts of Interest: The authors declare no conflict of interest with any other party.

\section{References}

1. Marr, A.; Marr, P. Entrapping homogeneous catalysts by sol-gel methods: The bottom-up synthesis of catalysts that recycle and cascade. Dalton Trans. 2011, 40, 20-26. [CrossRef] [PubMed]

2. Grasselli, R.K.; Sleight, A. Structure-Activity and Selectivity Relationships in Heterogeneous Catalysis; Elsevier: Amsterdam, The Netherlands, 1991; Volume 67.

3. De Pater, J.J.; Deelman, B.J.; Elsevier, C.J.; van Koten, G. Multiphase systems for the recycling of alkoxycarbonylation catalysts. Adv. Synth. Catal. 2006, 348, 1447-1458. [CrossRef]

4. Brintzinger, H.H.; Fischer, D.; Mülhaupt, R.; Rieger, B.; Waymouth, R.M. Stereospecific olefin polymerization with chiral metallocene catalysts. Angew. Chem. Int. Ed. Engl. 1995, 34, 1143-1170. [CrossRef] 
5. Shylesh, S.; Schünemann, V.; Thiel, W.R. Magnetically separable nanocatalysts: Bridges between homogeneous and heterogeneous catalysis. Angew. Chem. Int. Ed. 2010, 49, 3428-3459. [CrossRef] [PubMed]

6. Clark, J.H.; Macquarrie, D.J.; Mubofu, E.B. Preparation of a novel silica-supported palladium catalyst and its use in the Heck reaction. Green Chem. 2000, 2, 53-56. [CrossRef]

7. Mukhopadhyay, K.; Sarkar, B.R.; Chaudhari, R.V. Anchored Pd complex in MCM-41 and MCM-48: Novel heterogeneous catalysts for hydrocarboxylation of aryl olefins and alcohols. J. Am. Chem. Soc. 2002, 124, 9692-9693. [CrossRef] [PubMed]

8. Wan, B.; Liao, S.; Yu, D. Polymer-supported palladium-manganese bimetallic catalyst for the oxidative carbonylation of amines to carbamate esters. Appl. Catal. A 1999, 183, 81-84. [CrossRef]

9. McMorn, P.; Hutchings, G.J. Heterogeneous enantioselective catalysts: Strategies for the immobilisation of homogeneous catalysts. Chem. Soc. Rev. 2004, 33, 108-122. [CrossRef]

10. Horváth, I.T.; Rábai, J. Facile catalyst separation without water: Fluorous biphase hydroformylation of olefins. Science 1994, 266, 72-75. [CrossRef]

11. Collis, A.E.; Horvath, I.T. Heterogenization of homogeneous catalytic systems. Catal. Sci. Technol. 2011, 1, 912-919. [CrossRef]

12. Standfest-Hauser, C.M.; Lummerstorfer, T.; Schmid, R.; Hoffmann, H.; Kirchner, K.; Puchberger, M.; Trzeciak, A.M.; Mieczyńska, E.; Tylus, W.; Ziółkowski, J.J. Rhodium phosphine complexes immobilized on silica as active catalysts for 1-hexene hydroformylation and arene hydrogenation. J. Mol. Catal. A Chem. 2004, 210, 179-187. [CrossRef]

13. Thomas, J.M.; Raja, R. Catalytic significance of organometallic compounds immobilized on mesoporous silica: Economically and environmentally important examples. J. Organomet. Chem. 2004, 689, 4110-4124. [CrossRef]

14. Ma, Z.; Sun, W.H.; Zhu, N.; Li, Z.; Shao, C.; Hu, Y. Preparation of silica-supported late transition metal catalyst and ethylene polymerization. Polym. Int. 2002, 51, 349-352. [CrossRef]

15. Zhi, J.; Song, D.; Li, Z.; Lei, X.; Hu, A. Palladium nanoparticles in carbon thin film-lined SBA-15 nanoreactors: Efficient heterogeneous catalysts for Suzuki-Miyaura cross coupling reaction in aqueous media. Chem. Commun. 2011, 47, 10707-10709. [CrossRef] [PubMed]

16. Chen, Z.; Cui, Z.-M.; Niu, F.; Jiang, L.; Song, W.-G. Pd nanoparticles in silica hollow spheres with mesoporous walls: A nanoreactor with extremely high activity. Chem. Commun. 2010, 46, 6524-6526. [CrossRef] [PubMed]

17. Sadjadi, S.; Heravi, M.M.; Masoumi, B.; Kazemi, S.S. Pd (0) nanoparticles immobilized on multi-nitrogen functionalized Halloysite for promoting Sonogashira reaction: Studying the role of the number of surface nitrogens in catalytic performance. J. Coord. Chem. 2019, in press. [CrossRef]

18. Sadjadi, S.; Koohestani, F.; Bahri-Laleh, N.; Didehban, K. Halloysite nanoclay decorated with 2-amino pyrimidine functionalized poly glycidyl methacrylate: An efficient support for the immobilization of $\mathrm{Pd}$ nanoparticles. J. Solid State Chem. 2019, 271, 59-66. [CrossRef]

19. Oliveira, R.L.; He, W.; Gebbink, R.J.K.; de Jong, K.P. Palladium nanoparticles confined in thiol-functionalized ordered mesoporous silica for more stable Heck and Suzuki catalysts. Catal. Sci. Technol. 2015, 5, 1919-1928. [CrossRef]

20. Espinoza, R.; Snel, R.; Korf, C.; Nicolaides, C. Catalytic oligomerization of ethene over nickel-exchanged amorphous silica-aluminas; effect of the acid strength of the support. Appl. Catal. 1987, 29, 295-303. [CrossRef]

21. Nakagawa, Y.; Tomishige, K. Total hydrogenation of furan derivatives over silica-supported Ni-Pd alloy catalyst. Catal. Commun. 2010, 12, 154-156. [CrossRef]

22. Lee, K.H.; Lee, B.; Lee, K.R.; Yi, M.H.; Hur, N.H. Dual Pd and $\mathrm{CuFe}_{2} \mathrm{O}_{4}$ nanoparticles encapsulated in a core/shell silica microsphere for selective hydrogenation of arylacetylenes. Chem. Commun. 2012, 48, 4414-4416.

23. Khedkar, M.V.; Sasaki, T.; Bhanage, B.M. Immobilized palladium metal-containing ionic liquid-catalyzed alkoxycarbonylation, phenoxycarbonylation, and aminocarbonylation reactions. ACS Catal. 2013, 3, 287-293. [CrossRef]

24. Mane, R.S.; Sasaki, T.; Bhanage, B.M. Silica supported palladium-phosphine as a reusable catalyst for alkoxycarbonylation and aminocarbonylation of aryl and heteroaryl iodides. RSC Adv. 2015, 5, 94776-94785. [CrossRef] 
25. Bredenkamp, T.; Holzapfel, C. The Pd-catalysed hydromethoxycarbonylation of aliphatic internal alkenes with minimal double bond isomerisation. Catal. Commun. 2017, 96, 74-78. [CrossRef]

26. Kosswig, K.; Schaefer, W. Hydrocarboxymethylation-an Attractive Route from Olefins to Fatty Acid Esters? Ind. Eng. Chem. Prod. Res. Dev. 1980, 19, 330-334. [CrossRef]

27. Saphan, O.A.; Stephen, O.O. Methoxycarbonylation of olefins catalysed by homogeneous palladium(II) complexes of (phenoxy)imine ligands bearing alkoxy silane groups. Inorg. Chim. Acta 2019. Under review.

28. Knapen, J.W.; van der Made, A.W.; de Wilde, J.C.; van Leeuwen, P.W.; Wijkens, P.; Grove, D.M.; van Koten, G. Homogeneous catalysts based on silane dendrimers functionalized with arylnickel (II) complexes. Nature 1994, 372, 659. [CrossRef]

29. Anwander, R. Immobilization of molecular catalysts. In Handbook of Heterogeneous Catalysis; Wiley-VCH Verlag GmbH \& Co. KGaA: Weinheim, Germany, 2008; pp. 583-614.

30. Singh, G.; Saroa, A.; Khullar, S.; Mandal, S.K. Schiff bases of $\mathrm{N}$-(2-aminoethyl)-3-aminopropyltrimethoxysilane and its silatranes: Synthesis and characterization. J. Chem. Sci. 2015, 127, 679-685. [CrossRef]

31. Bhunia, S.; Jana, S.; Saha, D.; Dutta, B.; Koner, S. Catalytic olefin epoxidation over cobalt (II)-containing mesoporous silica by molecular oxygen in dimethylformamide medium. Catal. Sci. Technol. 2014, 4, 1820-1828. [CrossRef]

32. Polshettiwar, V.; Molnár, Á. Silica-supported Pd catalysts for Heck coupling reactions. Tetrahedron 2007, 63, 6949-6976. [CrossRef]

33. Bhunia, S.; Saha, D.; Koner, S. MCM-41-Supported Oxo-vanadium (IV) Complex: A Highly Selective Heterogeneous Catalyst for the Bromination of Hydroxy Aromatic Compounds in Water. Langmuir 2011, 27, 15322-15329. [CrossRef] [PubMed]

34. Sobhani, S.; Ghasemzadeh, M.S.; Honarmand, M.; Zarifi, F. Acetamidine-palladium complex immobilized on $\gamma-\mathrm{Fe}_{2} \mathrm{O}_{3}$ nanoparticles: A novel magnetically separable catalyst for Heck and Suzuki coupling reactions. RSC Adv. 2014, 4, 44166-44174. [CrossRef]

35. Huo, C.; Ouyang, J.; Yang, H. CuO nanoparticles encapsulated inside Al-MCM-41 mesoporous materials via direct synthetic route. Sci. Rep. 2014, 4, 3682. [CrossRef] [PubMed]

36. Hajjami, M.; Ghorbani, F.; Bakhti, F. MCM-41-N-propylsulfamic acid: An efficient catalyst for one-pot synthesis of 1-amidoalkyl-2-naphtols. Appl. Catal. A 2014, 470, 303-310. [CrossRef]

37. Durand, J.; Zangrando, E.; Stener, M.; Fronzoni, G.; Carfagna, C.; Binotti, B.; Kamer, P.C.; Müller, C.; Caporali, M.; van Leeuwen, P.W. Long-Lived Palladium Catalysts for CO/Vinyl Arene Polyketones Synthesis: A Solution to Deactivation Problems. Chem. Eur. J. 2006, 12, 7639-7651. [CrossRef] [PubMed]

38. Aguirre, P.A.; Lagos, C.A.; Moya, S.A.; Zúñiga, C.; Vera-Oyarce, C.; Sola, E.; Peris, G.; Bayón, J.C. Methoxycarbonylation of olefins catalyzed by palladium complexes bearing $\mathrm{P}, \mathrm{N}$-donor ligands. Dalton Trans. 2007, 46, 5419-5426. [CrossRef]

39. Tshabalala, T.A.; Ojwach, S.O.; Akerman, M.A. Palladium complexes of (benzoimidazol-2-ylmethyl) amine ligands as catalysts for methoxycarbonylation of olefins. J. Mol. Catal. A Chem. 2015, 406, 178-184. [CrossRef]

40. Zolezzi, S.; Moya, S.A.; Valdebenito, G.; Abarca, G.; Parada, J.; Aguirre, P. Methoxycarbonylation of olefins catalyzed by palladium (II) complexes containing naphthyl (diphenyl) phosphine ligands. Appl. Organomet. Chem. 2014, 28, 364-371. [CrossRef]

41. Kumar, K.; Darkwa, J. Palladium (II) complexes bearing mixed $\mathrm{N}^{\wedge} \mathrm{N}^{\wedge} \mathrm{X}(\mathrm{X}=\mathrm{O}$ and $\mathrm{S})$ tridentate ligands as pre-catalysts for the methoxycarbonylation of selected 1-alkenes. Polyhedron 2017, 138, 249-257. [CrossRef]

42. Chen, X.; Zhu, H.; Wang, T.; Li, C.; Yan, L.; Jiang, M.; Liu, J.; Sun, X.; Jiang, Z.; Ding, Y. The 2V-P, N polymer supported palladium catalyst for methoxycarbonylation of acetylene. J. Mol. Catal. A Chem. 2016, 414, 37-46. [CrossRef]

43. Tshabalala, T.A.; Ojwach, S.O. Tuning the regioselectivity of (benzimidazolylmethyl) amine palladium (II) complexes in the methoxycarbonylation of hexenes and octenes. Transit. Metal Chem. 2018, 43, 339-346. [CrossRef]

44. Alam, M.G.; Tshabalala, T.A.; Ojwach, S.O. Metal-Catalyzed Alkene Functionalization Reactions Towards Production of Detergent and Surfactant Feedstocks. J. Surfact. Deterg. 2017, 20, 75-81. [CrossRef]

45. Cypryk, M.; Apeloig, Y. Mechanism of the Acid-Catalyzed Si-O Bond Cleavage in Siloxanes and Siloxanols. A Theoretical Study. Organometallics 2002, 21, 2165-2175. [CrossRef] 
46. Tang, C.-M.; Li, X.-L.; Wang, G.-Y. A highly efficient catalyst for direct synthesis of methyl acrylate via methoxycarbonylation of acetylene. Korean J. Chem. Eng. 2012, 29, 1700-1707. [CrossRef]

47. Hendriksen, B.; Frenken, J. CO oxidation on Pt (110): Scanning tunneling microscopy inside a high-pressure flow reactor. Phys. Rev. Lett. 2002, 89, 046101. [CrossRef] [PubMed]

48. Mägerlein, W.; Beller, M.; Indolese, A.F. Palladium-catalyzed carbonylation of aryl halides-A detailed investigation of the alkoxycarbonylation of 4-bromoacetophenone. J. Mol. Catal. A Chem. 2000, 156, 213-221. [CrossRef]

49. Takegami, Y.; Yokokawa, C.; Watanabe, Y.; Masada, H.; Okuda, Y. Studies of the Organic Reactions of Metal Carbonyls. VI. The Isomerization of Acylcobalt Carbonyls-The Effects of Solvents and of the Structure of the Acyl Group. Bull. Chem. Soc. Jpn. 1965, 38, 787-791. [CrossRef]

50. Crocker, M.; Herold, R. Carbomethoxylation of ethylene catalysed by Pd (II) complexes intercalated in smectite clay. J. Mol. Catal. 1991, 70, 209-216. [CrossRef]

51. Dyson, P.J.; Jessop, P.G. Solvent effects in catalysis: Rational improvements of catalysts via manipulation of solvent interactions. Catal. Sci. Technol. 2016, 6, 3302-3316. [CrossRef]

52. Ziccarelli, I.; Neumann, H.; Kreyenschulte, C.; Gabriele, B.; Beller, M. Pd-Supported on N-doped carbon: Improved heterogeneous catalyst for base-free alkoxycarbonylation of aryl iodides. Chem. Commun. 2016, 52, 12729-12732. [CrossRef]

53. Ünver, H.; Yllmaz, F. Synthesis, Characterization, and Catalytic Hydrogenation Activity of New $\mathrm{N}-$ Acyl-Benzotriazole Rh (I) and Ru (III) Complexes in [bmim][BF4]. Catalysts 2016, 6, 147. [CrossRef]

54. Widegren, J.A.; Finke, R.G. A review of the problem of distinguishing true homogeneous catalysis from soluble or other metal-particle heterogeneous catalysis under reducing conditions. J. Mol. Catal. A Chem. 2003, 198, 317-341. [CrossRef]

55. Yu, K.; Sommer, W.; Weck, M.; Jones, C.W. Silica and polymer-tethered Pd-SCS-pincer complexes: Evidence for precatalyst decomposition to form soluble catalytic species in Mizoroki-Heck chemistry. J. Catal. 2004, 226, 101-110. [CrossRef]

56. Williams, D.B.G.; Lawton, M. Drying of organic solvents: Quantitative evaluation of the efficiency of several desiccants. J. Org. Chem. 2010, 75, 8351-8354. [CrossRef] [PubMed]

57. Burfield, D.R.; Smithers, R.H. Desiccant efficiency in solvent drying. 3. Dipolar aprotic solvents. J. Org. Chem. 1978, 43, 3966-3968. [CrossRef] [PubMed] 